SHOCK INITIATION EXPERIMENTS ON PBX 9501 EXPLOSIVE AT PRESSURES BELOW 3 GPa WITH ASSOCIATED IGNITION AND GROWTH MODELING

Steven K. Chidester, Darla G. Thompson, Kevin S. Vandersall, Deanne J. Idar, Craig M. Tarver, Frank Garcia, Paul A. Urtiew

June 15, 2007

14th American Physical Society Topical Conference on Shock Compression of Condensed Matter Kohala Coast, HI, United States June 24, 2007 through June 29, 2007 
This document was prepared as an account of work sponsored by an agency of the United States Government. Neither the United States Government nor the University of California nor any of their employees, makes any warranty, express or implied, or assumes any legal liability or responsibility for the accuracy, completeness, or usefulness of any information, apparatus, product, or process disclosed, or represents that its use would not infringe privately owned rights. Reference herein to any specific commercial product, process, or service by trade name, trademark, manufacturer, or otherwise, does not necessarily constitute or imply its endorsement, recommendation, or favoring by the United States Government or the University of California. The views and opinions of authors expressed herein do not necessarily state or reflect those of the United States Government or the University of California, and shall not be used for advertising or product endorsement purposes. 


\title{
SHOCK INITIATION EXPERIMENTS ON PBX 9501 EXPLOSIVE AT PRESSURES BELOW 3 GPa WITH ASSOCIATED IGNITION AND GROWTH MODELING
}

\author{
Steven K. Chidester ${ }^{1}$, Darla G. Thompson ${ }^{2}$, Kevin S. Vandersall ${ }^{1}$, Deanne J. Idar ${ }^{2}$, \\ Craig M. Tarver ${ }^{1}$, Frank Garcia ${ }^{1}$, and Paul A. Urtiew ${ }^{1}$ \\ ${ }^{1}$ Lawrence Livermore National Laboratory, Livermore, CA 94550 \\ ${ }^{2}$ Los Alamos National Laboratory, Los Alamos, NM 87545
}

\begin{abstract}
Shock initiation experiments on the explosive PBX 9501 (95\% HMX, 2.5\% estane, and $2.5 \%$ nitroplasticizer by weight) were performed at pressures below $3 \mathrm{GPa}$ to obtain in-situ pressure gauge data, run-distance-to-detonation thresholds, and Ignition and Growth modeling parameters. Propellant driven gas guns $(101 \mathrm{~mm}$ and $155 \mathrm{~mm})$ were utilized to initiate the PBX 9501 explosive with manganin piezoresistive pressure gauge packages placed between sample slices. The run-distance-to-detonation points on the Pop-plot for these experiments showed agreement with previously published data and Ignition and Growth modeling parameters were obtained with a good fit to the experimental data. This parameter set will allow accurate code predictions to be calculated for safety scenarios in the low-pressure regime (below $3 \mathrm{GPa}$ ) involving PBX 9501 explosive.
\end{abstract}

Keywords: Explosive, PBX 9501, shock to detonation transition, ignition and growth PACS: 82.33.Vx, 82.40.Fp

\section{INTRODUCTION}

Interest exists in studying safety to shock impact of HMX (octahydro-1,3,5,7-tetranitro1,3,5,7-tetrazocine) based explosives such as the commonly used PBX 9501 (95\% HMX, 2.5\% estane, and 2.5\% BDNPA-F nitroplasticizer by weight). Prior studies on PBX 9501 include wedge tests [1], embedded particle velocity gauges [2-4], VISAR at low input shock pressures $[5,6]$, and embedded manganin gauges $[7,8]$ at both ambient and elevated temperature. Other HMX based explosives, such as LX-04 (85\% HMX, 15\% Viton) [9] and PBX 9404 [10] have also been studied in the low-pressure regime below $3 \mathrm{GPa}$. In this paper, the shock sensitivity of PBX 9501 at pressures below 3 GPa was measured using embedded manganin pressure gauges.

\section{EXPERIMENTAL PROCEDURE}

Shock initiation experiments were performed on the explosive PBX 9501 using the $101 \mathrm{~mm}$ diameter propellant driven gas gun at the Lawrence Livermore National Laboratory (LLNL) main site or a $155 \mathrm{~mm}$ diameter smooth bore Howitzer gun located at LLNL Site 300 (bunker 850). The projectile consisted of either a micarta tube polycarbonate end caps $(101 \mathrm{~mm}$ gun) or an aluminum 6061-T6 sabot $(155 \mathrm{~mm}$ 
gun) with a 6061-T6 Aluminum flyer plate on the impact surface.

The explosive was in the form of thin disks with gauge packages inserted in between with a total explosive thickness as high as $80 \mathrm{~mm}$ for the $155 \mathrm{~mm}$ gun shots. For the $101 \mathrm{~mm}$ gun experiments, the explosive discs were $90 \mathrm{~mm}$ in diameter and either 5 or $10 \mathrm{~mm}$ thick stacked to the final thickness. The $155 \mathrm{~mm}$ gun shots used $145 \mathrm{~mm}$ diameter by $10 \mathrm{~mm}$ thick discs.

The manganin piezoresistive foil pressure gauges placed within the explosive sample were "armored" with sheets of Teflon insulation on each side of the gauge. Manganin is a coppermanganese alloy that changes electrical resistance with pressure (i.e. piezoresistive). Also used were PZT Crystal pins to measure the projectile velocity and tilt (planarity of impact). During the experiment, oscilloscopes measure change of voltage as result of resistance change in the gauges which were then converted to pressure using the hysteresis corrected calibration curve published elsewhere $[11,12]$.

From the data of the shock arrival times of the gauge locations, a plot of distance vs. time ("x-t plot") is constructed with the slope of the plotted lines yielding the shock velocities with two lines apparent, a line for the un-reacted state as it reacts and a line representing the detonation velocity. The intersection of these two lines is taken as the "run-distance-todetonation," which is then plotted on the "PopPlot" showing the run-distance-to-detonation as a function of the input pressure in log-log space.

\section{REACTIVE FLOW MODELING}

The Ignition and Growth reactive flow model [13] uses two Jones-Wilkins-Lee (JWL) equations of state in the form:

$$
p=A e^{-R_{1} V}+B e^{-R_{2} V}+\omega C_{V} T / V
$$

where $\mathrm{p}$ is pressure in Megabars, $\mathrm{V}$ is relative volume, $\mathrm{T}$ is temperature, $\omega$ is the Gruneisen coefficient, $\mathrm{C}_{\mathrm{V}}$ is the average heat capacity, and $\mathrm{A}, \mathrm{B}, \mathrm{R}_{1}$ and $\mathrm{R}_{2}$ are constants. The equations of state are fitted to the available shock
Hugoniot and product expansion data. Table 1 contains the modeling parameters and reaction rate constants for these experiments. The reaction rate equation is:

$$
\begin{aligned}
& d F / d t=\underbrace{I(1-F)^{b}\left(\rho / \rho_{0}-1-a\right)^{x}}_{0<F<F_{I_{\max }}}+ \\
& \underbrace{G_{1}(1-F)^{c} F^{d} p^{y}}_{0<F<F_{G_{1} \max }}+\underbrace{G_{2}(1-F)^{e} F^{g} p^{z}}_{F_{G_{2} \min }<F<1}
\end{aligned}
$$

where $\mathrm{F}$ is the fraction reacted, $\mathrm{t}$ is time in $\mu \mathrm{s}, \rho$ is the current density in $\mathrm{g} / \mathrm{cm}^{3}, \rho_{O}$ is the initial density (calculated based on thermal expansion data), $p$ is pressure in Mbars, and $\mathrm{I}_{1} \mathrm{G}_{1}, \mathrm{G}_{2}$, a, $\mathrm{b}, \mathrm{c}, \mathrm{d}, \mathrm{e}, \mathrm{g}, \mathrm{x}, \mathrm{y}$, and $\mathrm{z}$ are constants. This reaction rate law models the three stages of reaction generally observed during shock initiation of solid explosives. Table 2 details the Gruneisen parameters used.

Table 1. Ignition and Growth modeling parameters.

\begin{tabular}{|c|c|}
\hline \multicolumn{2}{|c|}{ MATERIAL PARAMETERS } \\
\hline $\begin{array}{c}\text { Shear Modulus }=0.0354 \\
\text { Mbar }\end{array}$ & $\begin{array}{c}\text { Yield Strength }=0.002 \\
\text { Mbar }\end{array}$ \\
\hline $\mathrm{T}_{\mathrm{O}}=298^{\circ} \mathrm{K}$ & $\rho_{0}=1.832 \mathrm{~g} / \mathrm{cm}^{3}$ \\
\hline \multicolumn{2}{|c|}{ REACTION RATES } \\
\hline $\mathrm{a}=0.0819$ & $\mathrm{x}=4.0$ \\
\hline $\mathrm{b}=0.667$ & $\mathrm{y}=2.0$ \\
\hline $\mathrm{c}=0.667$ & $\mathrm{z}=3.0$ \\
\hline $\mathrm{d}=0.667$ & $\mathrm{~F}_{\text {igmax }}=0.02$ \\
\hline $\mathrm{e}=0.333$ & $\mathrm{~F}_{\mathrm{G} 1 \mathrm{max}^{-}=0.5}$ \\
\hline $\mathrm{g}=1.0$ & $\mathrm{~F}_{\mathrm{G} 2 \mathrm{~min}=0.5}$ \\
\hline $\mathrm{I}=20000 \mu \mathrm{s}^{-1}$ & $\mathrm{G}_{1}=285 \mathrm{Mbar}^{-2} \mu \mathrm{s}^{-1}$ \\
\hline- & $\mathrm{G}_{2}=320 \mathrm{Mbar}^{-2} \mu \mathrm{s}^{-1}$ \\
\hline
\end{tabular}

Table 2. Gruneisen parameters for inert materials.

\begin{tabular}{|c|c|c|c|c|c|c|c|}
\hline INERT & $\begin{array}{c}\rho_{0} \\
(\mathrm{~g} / \mathrm{cc})\end{array}$ & $\begin{array}{c}\mathrm{C} \\
(\mathrm{km} / \mathrm{s})\end{array}$ & $\mathrm{S}_{1}$ & $\mathrm{~S}_{2}$ & $\mathrm{~S}_{3}$ & $\gamma_{0}$ & $\mathrm{a}$ \\
\hline $\begin{array}{l}6061- \\
\text { T6 Al }\end{array}$ & 2.703 & 5.24 & 1.4 & 0.0 & 0.0 & 1.97 & 0.48 \\
\hline Teflon & 2.15 & 1.68 & 1.123 & 3.98 & -5.8 & 0.59 & 0.0 \\
\hline
\end{tabular}




\section{RESULTS/DISCUSSION}

Table 3 contains the experimental flyer velocities, impact pressures, and run distances to detonation for the two PBX 9501 experiments performed.

The resulting data points are plotted on the Pop-plot as shown in Figure 1 and compares well to previous data. The in-situ gauge records are shown in Figures 2 and 4 for experiments 4728 and HG07-02 respectively. An increase in pressure can be observed as the shock progresses through and reacts the explosive material until a full detonation is observed. Ignition and Growth reactive flow modeling results are shown in Figures 3 and 5 in the form of simulated gauge records. They simulate the experimental records in Figures 2 and 4 respectively. From comparing these records a good agreement can be seen.

Table 3. Summary of PBX 9501 gun experiments.

\begin{tabular}{|c|c|c|c|}
\hline SHOT & $\begin{array}{c}\text { IMPACT } \\
\text { VELOCITY }\end{array}$ & $\begin{array}{c}\text { INPUT } \\
\text { PRESSURE }\end{array}$ & $\begin{array}{c}\text { RUN TO } \\
\text { DET }\end{array}$ \\
\hline HG07-02 & $0.351 \mathrm{~km} / \mathrm{s}$ & $1.45 \mathrm{GPa}$ & $72.2 \mathrm{~mm}$ \\
\hline 4728 & $0.889 \mathrm{~km} / \mathrm{s}$ & $2.56 \mathrm{GPa}$ & $16.9 \mathrm{~mm}$ \\
\hline
\end{tabular}

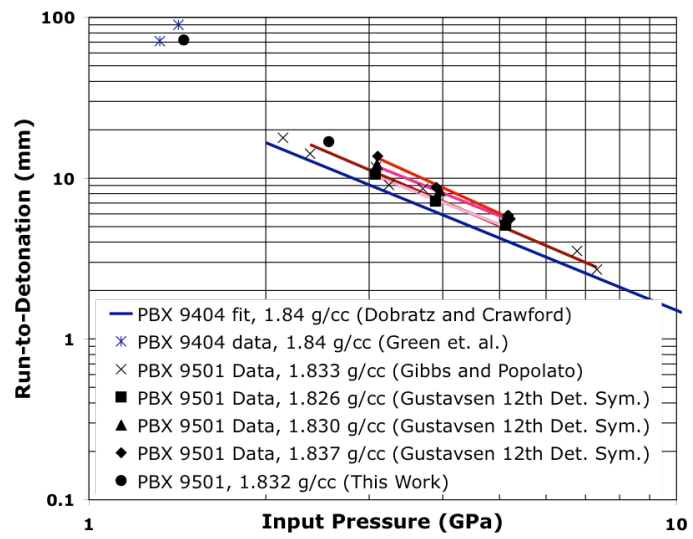

FIGURE 1. Pop-Plot comparing the data from this work with that of previous experiments.

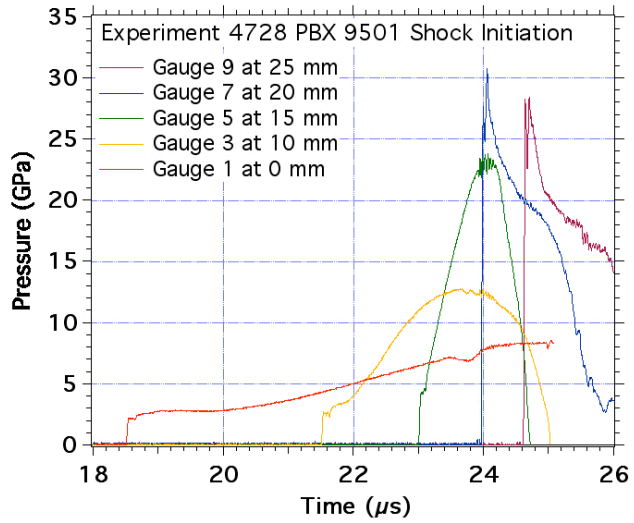

FIGURE 2. Experimental pressure histories for PBX 9501 impacted by an aluminum flyer plate at $889 \mathrm{~m} / \mathrm{s}$.

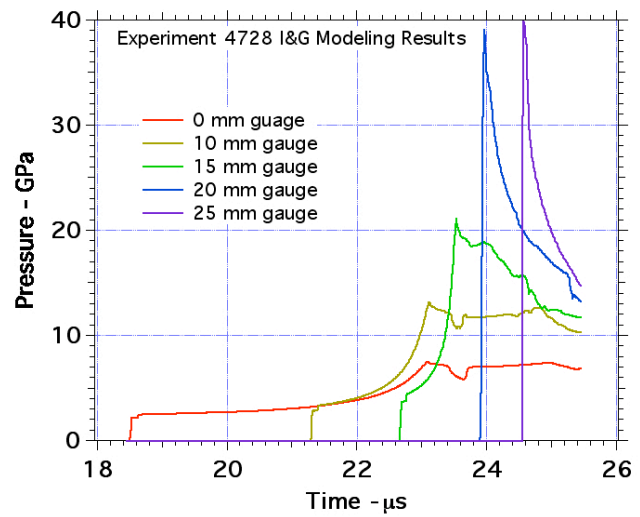

FIGURE 3. Calculated pressure histories for PBX 9501 impacted by an aluminum flyer plate at $889 \mathrm{~m} / \mathrm{s}$.

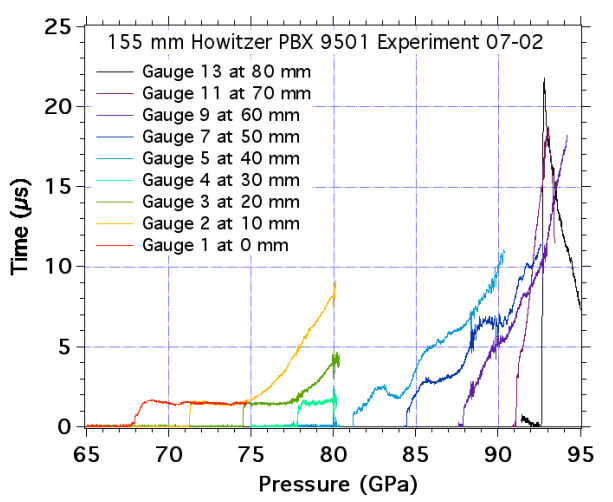

FIGURE 4. Experimental pressure histories for PBX 9501 impacted by an aluminum flyer plate at $351 \mathrm{~m} / \mathrm{s}$. 


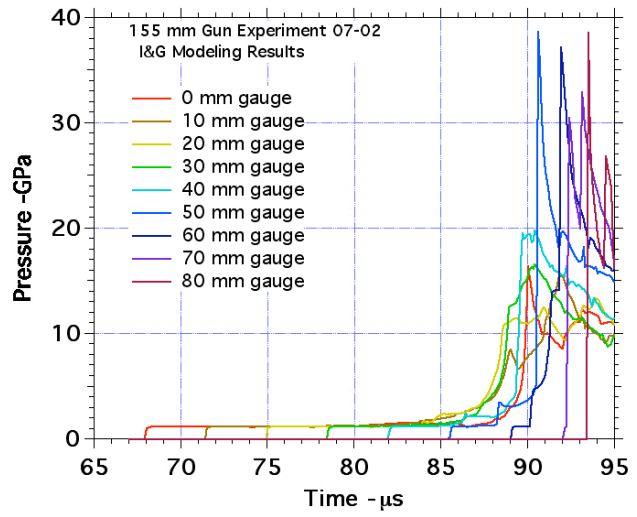

FIGURE 5. Calculated pressure histories for PBX 9501 impacted by an aluminum flyer plate at $351 \mathrm{~m} / \mathrm{s}$.

\section{SUMMARY}

Shock initiation experiments on the explosive PBX 9501 (95\% HMX, 2.5\% estane, and 2.5\% nitroplasticizer by weight) were performed to obtain in-situ pressure gauge data and Ignition and Growth modeling parameters. The rundistance-to-detonation points on the Pop-plot for these experiments showed agreement with previously published data and Ignition and Growth modeling parameters were obtained with a good fit to the experimental data.

\section{ACKNOWLEDGEMENTS}

Special thanks go to the $101 \mathrm{~mm}$ and $155 \mathrm{~mm}$ gun crews. This work was performed under the auspices of the U. S. Department of Energy by the University of California, Lawrence Livermore National Laboratory under Contract No. W-7405Eng-48.

\section{REFERENCES}

1. LASL Explosive Property Data, Terry R. Gibbs and Alphonse Popolato, Editors, University of California Press, pp. 353-358, 1980.

2. Sheffield, S. A., Gustavsen, R. L., Hill, L. G., and Alcon, R. R., Eleventh International Detonation Symposium, ONR 33300-5, Snommass, CO, 1998, pp. 451-458.

3. Sheffield, S. A., Gustavsen, R. L., and Alcon, R. R., Shock Compression of Condensed Matter-1999, M.
D. Furnish, L. C. Chhabildas, and R. S. Hixson, eds., AIP Conference Proceedings 505, Snowbird, UT, 1999, pp. 1043-1048.

4. Gustavsen, R. L., Sheffield, S. A., Alcon, R. R., and Hill, L. G., "Shock Initiation of New and Aged PBX 9501," Proceedings of the $12^{\text {th }}$ International Symposium on Detonation, San Diego, CA, August, 2002, pp. 530-537.

5. Dick, J. J., Shock Compression of Condensed Matter1999, Furnish, M. D Chhabildas, L. C., and Hixson, R. S.,eds., AIP Conference Proceedings 505, Snowbird, UT, 1999, pp. 683-686.

6. Dick, J, J., Martinez, A. R., and Hixson, R. S., Eleventh International Detonation Symposium, ONR 33300-5, Snommass, CO, 1998, pp. 317-324.

7. Tarver, C. M., Forbes, J. W., Urtiew, P. A., Garcia, F., "Shock Sensitivity of LX-04 at $150^{\circ} \mathrm{C}$," Shock Compression of Condensed Matter-1999, pp.891-894.

8. Kevin S. Vandersall, Craig M. Tarver, Frank Garcia, and Paul A. Urtiew, "Shock Initiation Experiments on PBX9501 Explosive at $150^{\circ} \mathrm{C}$ for Ignition and Growth Modeling," Shock Compression of Condensed Matter - 2005, AIP Conference Proceedings 845, Baltimore Maryland, 2006, pp. 1127-1130.

9. Kevin S. Vandersall, Craig M. Tarver, Frank Garcia, Steven K. Chidester, Paul A. Urtiew and Jerry W. Forbes, "Low Amplitude Single and Multiple Shock Initiation Experiments and Modeling of LX-04," 13th International Detonation Symposium, Norfolk, VA, July $23-28,2006$, in press.

10. Green, L., Nidick, E., Lee, E., and Tarver, C. "Reactions in PBX 9404 from Low Amplitude Shock Waves," Symposium on Behavior of Dense Media Under High Dynamic Pressures, April 27-31, Paris, France, 1978.

11. Vantine, H.C., Erickson, L.M. and Janzen, J., "Hysteresis-Corrected Calibration of Manganin under Shock Loading", J. Appl. Phys., 51 (4), April 1980.

12. Vantine H., Chan J., Erickson L. M., Janzen J., Lee R. and Weingart R. C., "Precision Stress Measurements in Severe Shock-Wave Environments with Low Impedance Manganin Gauges," Rev. Sci. Instr., 51. pp. 116-122 (1980).

13. Tarver, C. M., Hallquist, J. O., and Erikson, L. M., "Modeling Short Pulse Duration Shock Initiation of Solid Explosives," Eighth Symposium (International) on Detonation, Naval Surface Weapons Center NSWC MP86-194, Albuquerque, NM, 1985, pp. 951-961. 